EDUARDO PASCHOIN DE OLIVEIRA CAMPOS

\title{
ASPECTOS JURÍDICOS DA SECURITIZAÇÃO DE DIREITOS CREDITÓRIOS DO AGRONEGÓCIO NO MERCADO DE CAPITAIS BRASILEIRO
}

Dissertação de Mestrado

Professor Associado Dr. HARoldo MALHeiros DuClerc VerÇosa

FACULDADE DE DIREITO DA UNIVERSIDADE DE SÃO PAULO

SÃO PAULO

2019 


\title{
ASPECTOS JURÍDICOS DA SECURITIZAÇÃO DE DIREITOS CREDITÓRIOS DO AGRONEGÓCIO NO MERCADO DE CAPITAIS BRASILEIRO
}

\begin{abstract}
Dissertação apresentada à Banca Examinadora do Programa de Pós-Graduação em Direito da Faculdade de Direito da Universidade de São Paulo, como exigência parcial para obtenção do título de Mestre em Direito na área de concentração Direito Comercial, sob a orientação do Professor Associado Dr. Haroldo Malheiros Duclerc Verçosa.
\end{abstract}

FACULDADE DE DIREITO DA UNIVERSIDADE DE SÃO PAULO SÃO PAULO 
Campos, Eduardo Paschoin de Oliveira

ASPECTOS JURIDICOS DA SECURITIZAÇÃO DE DIREITOS

CREDITÓRIOS DO AGRONEGÓCIO NO MERCADO DE CAPITAIS

BRASILEIRO ; Eduardo Paschoin de Oliveira Campos;

orientador Haroldo Malheiros Duclerc Verçosa -- São

Paulo, 2019.

123

Dissertação (Mestrado - Programa de Pós-Graduação em Direito Comercial) - Faculdade de Direito, Universidade de São Paulo, 2019.

1. SECURITIZAÇÃO. 2. AGRONEGÓCIO. 3. MERCADO DE CAPITAIS. 4. DIREITO COMERCIAL. 5. CVM. I. Verçosa, Haroldo Malheiros Duclerc, orient. II. Título. 


\section{AGRADECIMENTO}

Primeiramente, ao professor Verçosa por ter acreditado no meu trabalho e participado ativamente na construção desse sonho da pós-graduação na USP. Suas aulas e os seminários me deram a certeza de que algum dia eu quero estar na frente de uma sala de aula, trocando experiências com todos ali presentes.

A todos aqueles que participaram de alguma forma na construção desse sonho, os quais destaco Renato Buranello, por ter ouvido minhas ideias, criticado e encorajado a seguir em frente; Cris Yamaji, que plantou essa semente na cabeça de um jovem advogado; Denise Okimura, que foi sempre tão compreensiva nas horas em que eu tinha que preparar textos ou fugir do escritório para assistir às aulas; Thiago Giantomassi, por toda a compreensão e parceria e à Renata Mendes, que leu meu currículo mal formatado no início da carreira e me deu a oportunidade de trabalhar com mercado de capitais. Sem vocês nada disso seria possível.

Aos meus colegas e amigos de trabalho por toda a compreensão no dia a dia e por me ensinarem tanto com as experiências que trocamos, as quais foram refletidas em diversas páginas deste trabalho.

Aos meus pais José Eduardo e Elizabeth Campos e à minha irmã Maíra Campos. Vocês são a base de tudo e não há palavras que eu possa utilizar neste contexto para expressar o quanto reconheço e sou grato pelo que fizeram por mim.

À minha amada noiva, Maria Alice, pelas inúmeras vezes nesse processo em que você colocou minha cabeça no lugar e me fez focar em cada passo do caminho.

A todos aqueles que contribuíram de alguma forma com a minha trajetória.

Por fim, e não menos importante, a Deus. 
DEDICATÓRIA

Dedico este trabalho aos meus pais e à Maria Alice, por toda a força e amor que me deram neste processo. 


\section{RESUMO}

CAMPOS. Eduardo Paschoin de Oliveira. Aspectos Jurídicos da Securitização de Direitos Creditórios do Agronegócio no Mercado de Capitais Brasileiro. 120 folhas. Mestrado - Faculdade de Direito, Universidade de São Paulo, São Paulo, 2019.

O financiamento ao agronegócio no Brasil foi sempre muito dependente de recursos e políticas públicas. Desde a década de 1990, novos instrumentos financeiros vêm sendo criados para fomentar sua atratividade e acesso à recursos privados, os quais foram analisados detalhadamente ao longo deste trabalho. O mercado de capitais se faz cada vez mais importante para criar pontes entre os integrantes do setor e a poupança popular. Nesse contexto surge a securitização de direitos creditórios do agronegócio, que consiste na vinculação de um fluxo de recebíveis originados no setor a um título ou valor mobiliário para colocação junto ao público investidor. Por ser um processo complexo do ponto de vista jurídico, foram analisados seus aspectos essenciais neste trabalho, que envolvem a importância de um negócio subjacente gerador de prestações financeiras diferidas ao longo do tempo, cessão de crédito definitiva em caráter true sale em favor de um veículo (fundo de investimento ou companhia securitizadora de direitos creditórios do agronegócio) e sua titularização ou securitização materializada em um novo instrumento de maior liquidez e atratividade. Embora seja um processo complexo, a securitização deve ser analisada como um negócio jurídico único. 


\begin{abstract}
CAMPOS. Eduardo Paschoin de Oliveira. Legal Aspects of the Securitization of Agribusiness Credit Rights in the Brazilian Capital Markets. 120 pages. Master - Faculty of Law, University of São Paulo, São Paulo, 2019.

The financing of agribusiness in Brazil has always been very dependent public funds and policies. Since the 1990s, new financial instruments have been created to reduce such dependence, fostering its attractiveness and access to private resources. These financial instruments are analyzed in detail throughout this dissertation. In this context, the capital market becomes increasingly important in the creation of connections between the agribusiness' players and the investors. This is where the securitization agribusiness credit rights come in. Such transactions consist of linking a flow of receivables originated in the agribusiness sector to a bond or security. As a complex process from the legal point of view, its essential aspects were analyzed in this work, which involves (i) the importance of an underlying transaction that generates deferred financial flow over time, (ii) definitive credit assignment in true sale character on behalf of a vehicle (investment fund or agribusiness credit rights' securitization company) and (iv) its securitization, materialized in a new instrument of greater liquidity and attractiveness. Aspects of the credit rights originated in the agribusiness that give them different legal treatment were also analyzed.
\end{abstract}

Keywords: Agribusiness; securitization; CRA; FIDC. 


\section{SUMÁRIO}

1. INTRODUÇÃO

2. SISTEMA FINANCEIRO NACIONAL - LINHAS GERAIS ............................ 17

2.1. Poupança, investimento e intermediação financeira .................................... 17

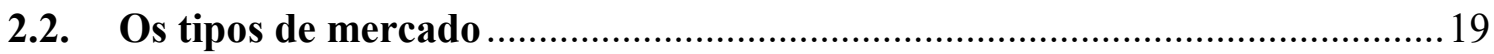

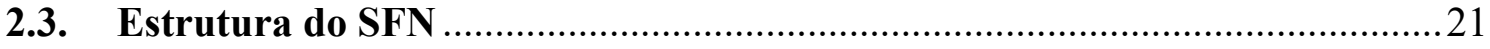

3. FINANCIAMENTO PÚBLICO E PRIVADO AO AGRONEGÓCIO ................2 24

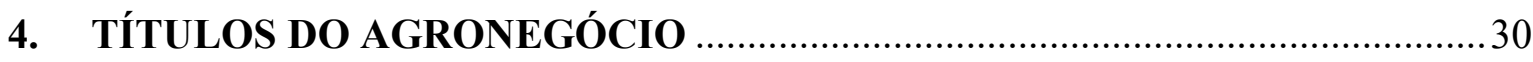

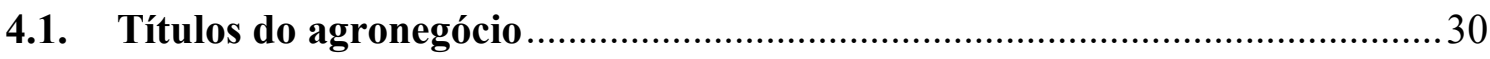

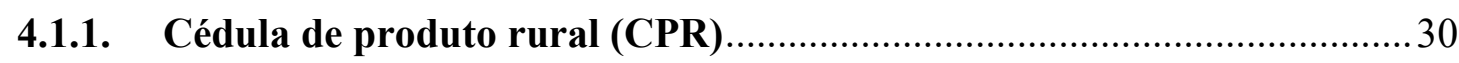

4.1.2. Certificado de depósito agropecuário e warrant agropecuário

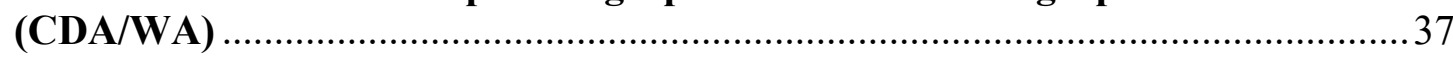

4.1.3. Certificado de direitos creditórios do agronegócio (CDCA) ....................4 42

4.1.4. Letra de crédito do agronegócio (LCA) ...................................................49

4.1.5. Certificado de recebíveis do agronegócio (CRA) .....................................54

5. SECURITIZAÇÃO E O AGRONEGÓCIO NO BRASIL .....................................57

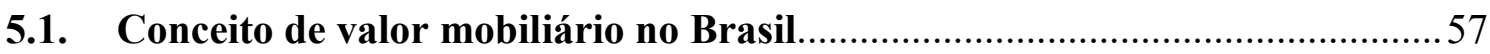

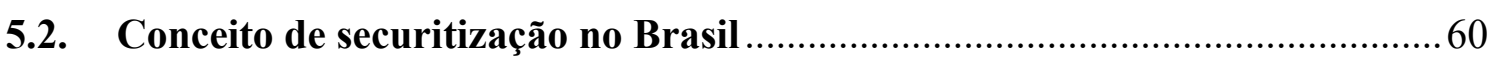

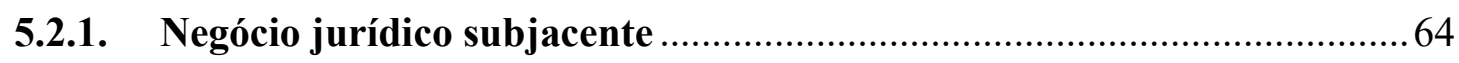

5.2.2. Transferência, aquisição e vinculação dos recebíveis................................66

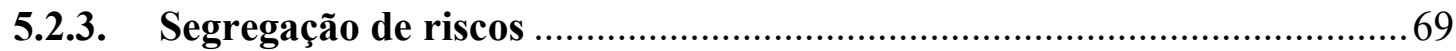

5.3. Certificado de recebíveis do agronegócio (CRA) …...................................... 70

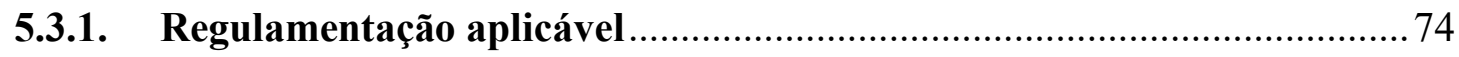

5.3.2. Revolvência: vinculação de novos direitos creditórios do agronegócio .. 76

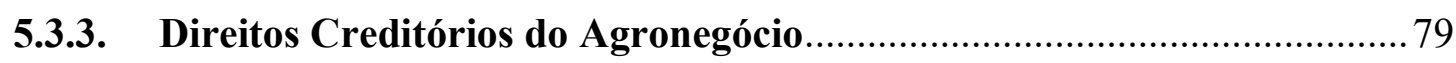

5.3.4. Tratamento tributário e benefício fiscal ................................................. 90

5.3.5. Remuneração dos CRA com base na variação cambial ........................... 94

5.4. Agronegócio e os Fundos de investimento em direitos creditórios (FIDC)....96

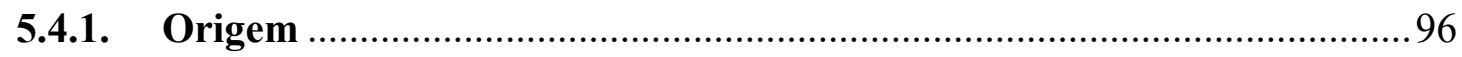

5.4.2. Natureza e Composição de Carteira .........................................................99

5.4.3. Direitos creditórios padronizados e não-padronizados ......................... 102

5.5. Notas Finais sobre a Securitização de Direitos Creditórios do Agronegócio ....

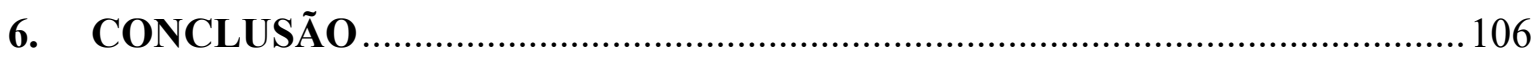

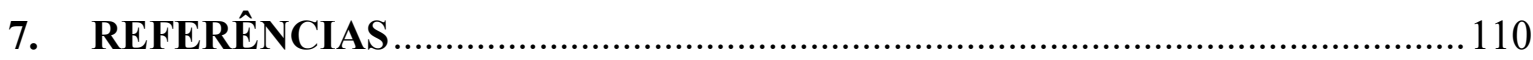




\section{Glossário de Siglas e Abreviaturas utilizadas neste trabalho}

CNA Confederação da Agricultura e Pecuária do Brasil - CNA

B3 B3 S.A. - Brasil, Bolsa, Balcão

BACEN Banco Central do Brasil

$\mathrm{CC}$

Lei $\mathrm{n}^{\mathrm{o}} 10.406$, de 10 de janeiro de 2002

CDA

Certificado de Depósito Agropecuário

CDCA

Certificado de Direitos Creditórios do Agronegócio

CMN

Conselho Monetário Nacional

CNPC

Conselho Nacional de Previdência Complementar

CNSP

Conselho Nacional de Seguros Privados

COFINS Contribuição para Financiamento da Seguridade Social

CF/88

Constituição da República Federativa do Brasil de 1988

CPC

Lei $\mathrm{n}^{\circ} 13.105$, de 16 de março de 2015.

CPR

Cédula de Produto Rural

CPR-F

Cédula de Produto Rural - Modalidade Financeira

CRA

Certificado de Recebíveis do Agronegócio

CRI

Certificado de Recebível Imobiliário

CRSFN Conselho de Recursos do Sistema Financeiro Nacional

CSLL Contribuição Social sobre o Lucro Liquido

CTN

Lei $\mathrm{N}^{\circ}$ 5.172, de 25 de outubro de 1966.

CVM

Comissão de Valores Mobiliários

FIDC

Fundos de Investimento em Direitos Creditórios

FIDC-NP

Fundos de Investimento em Direitos Creditórios Não

ICMS

Padronizados - FIDC NP

Imposto Sobre Circulação de Mercadorias e Prestação de Serviços

INCRA Instituto Nacional da Colonização e Reforma Agrária

IOF Imposto sobre Operações Financeiras

IRPJ Imposto sobre a renda aplicável a essas pessoas jurídicas

IRRF Imposto de Renda Retido na Fonte

LCA Letra de Crédito do Agronegócio

LCI Letras de Crédito Imobiliárias 
MAPA

PFE

PIB

PIS

CETIP UTVM

ou CETIP

SFN

SNCR

SRE

STJ

SUMOC

WA
Ministério da Agricultura, Pecuária e Abastecimento MAPA

Procuradoria Federal Especializada junto à CVM integrante da estrutura da Procuradoria-Geral Federal PGF

Produto Interno Bruto

Programa de Integração Social

Segmento CETIP Unidade de Títulos e Valores Mobilários da B3.

Sistema Financeiro Nacional

Sistema Nacional de Crédito Rural

Superintendência de Registros de Valores Mobiliários da CVM

Superior Tribunal de Justiça

Superintendência da Moeda e do Crédito

Warrant Agropecuário 


\section{INTRODUÇÃO}

Esta dissertação versa sobre os "Aspectos Jurídicos da Securitização de Direitos Creditórios do Agronegócio no Mercado de Capitais Brasileiro".

De acordo com a CNA, o agronegócio brasileiro representou, em 2017, aproximadamente $23,5 \%{ }^{1}$ do PIB, gerando cerca de $\mathrm{R} \$ 96$ bilhões $^{2}$ em faturamento para as exportações brasileiras, além de ser um dos maiores responsáveis pelos superávits comerciais do país. Por sua vez, o MAPA estima que a produção do agronegócio brasileiro alcance, neste ano, o volume de aproximadamente 234 milhões de toneladas de grãos, o que demonstra o evidente crescimento do setor no Brasil.

Nos termos do "Plano Agrícola e Pecuário 2017/2018" do MAPA ${ }^{3}$, as condições favoráveis das quais o Brasil dispõe para a produção agropecuária - recursos naturais abundantes, tecnologia avançada, capacidade de gestão e política agrícola adequada asseguram a vantagem comparativa do país e sua capacidade de expansão da oferta, credenciando-o como um dos principais supridores da demanda mundial por alimentos e matérias-primas agropecuárias.

Dada a peculiaridade das relações travadas no setor e à sua importância para o desenvolvimento social e econômico do país, seu desenvolvimento precisou se dar por mecanismos diferenciados de financiamento, chamados de políticas de crédito rural, os quais foram por muitos anos responsáveis por viabilizar a concessão de crédito ao setor a taxas de juros e condições de pagamento fora do usual para as épocas em que foram implantadas.

Nessa linha, em 1965, foi instituído o SNCR, responsável por instituir as diretrizes da política de crédito a ser formulada pelo $\mathrm{CMN}$, em consonância com a política de desenvolvimento agropecuário do país.

Entre o começo da década de 1960 até o final dos anos 70, o SNRC proporcionou uma grande oferta de crédito para o agronegócio, viabilizando a sua modernização e foco na produção de grãos. Nesse contexto desenvolveram-se atividades de pesquisa agropecuária,

\footnotetext{
${ }^{1}$ Confederação da Agricultura e Pecuária do Brasil. Agro mais maduro e moderno. Disponível em: http://www.cnabrasil.org.br/artigos/agro-maduro-e-moderno. Acesso em 17 maio. 2017

${ }^{2}$ Centro de Estudos Avançados em Economia Aplicada - ESALQ/USP. Índices de Exportação do Agronegócio $2017 . \quad$ p. $2 . \quad$ Disponível em: $<$ https://www.cepea.esalq.usp.br/upload/kceditor/files/Cepea_ExportAgro_2017_(1).pdf $>$.

${ }^{3}$ BRASIL. Ministério da Agricultura, Pecuária e Abastecimento. Plano agrícola e pecuário 2014/2015. Disponível em $<\mathrm{http}$ //www.agricultura.gov.br/assuntos/sustentabilidade/plano-agricola-e-pecuario/arquivospap/folder-pap-2017-18>. Acesso em> 22 de maio de 2018.
} 
novas técnicas de cultura, armazenamento, industrialização de matérias primas etc. ${ }^{4}$ Contudo conforme exploraremos mais a fundo nesta dissertação, o SNCR, por diversos fatores, começou a apresentar dificuldades operacionais e, no início dos anos 80, problemas como o desequilíbrio entre as fontes de captação de recursos e a demanda dos integrantes da cadeia agroindustrial, aliados à ineficácia de grande parte das produções financiadas, com consequente elevação na inadimplência, levaram à redução do crédito oficial em valor inferior ao quíntuplo do que era oferecido na década anterior. ${ }^{5}$

Com a escassez de recursos públicos e a ineficiência dos títulos de crédito rural existentes à época, os subsídios foram eliminados aos poucos, abrindo espaço para bancos privados oferecerem linhas de crédito paralelas, sem ou com participação reduzida do governo, o que elevou o custo da captação de recursos para o desenvolvimento do agronegócio.

Embora a produtividade continuasse a crescer no setor ${ }^{6}$, o agronegócio deixou de ter fontes subsidiadas de financiamento, dependendo quase que exclusivamente do custo de captação arbitrado pelas linhas paralelas que nem sempre se demonstrava atrativo ou moldado para atender às demandas dos modelos de negócios que integram o setor. ${ }^{7}$.

Tal situação perdurou até o início da década de 90, quando foi inserido em nosso sistema jurídico o primeiro título moderno do agronegócio, a CPR, disciplinada pela Lei $\mathrm{n}^{\circ}$ 8.929/94, que se tornou o principal título de crédito com capilaridade junto à poupança popular destinado ao financiamento e desenvolvimento do agronegócio brasileiro. Sua criação teve como principal objetivo oferecer ao mercado de crédito agrícola um instrumento próprio de financiamento à produção que trouxesse em seu bojo características como a simplicidade, eficácia, garantias para as partes envolvidas e baixo custo operacional.

\footnotetext{
${ }^{4}$ BELIK. W. Paulillo, L.F. Mudanças no Financiamento da Produção Agrícola Brasileira. Disponível em: < http://www.fao.org/tempref/GI/Reserved/FTP_FaoRlc/old/prior/desrural/brasil/Belik.PDF>. Acesso em: 09 jan. 2018

${ }^{5}$ RAMOS. Simone Yuri. Evolução da Política de Crédito Rural Brasileira/ Simone Yuri Ramos, Geraldo Buenoi Martha Júnior - Planaltina, DF: Embrapa Cerrados, 2010. p. 1. Disponível em: $<$ http://bbeletronica.cpac.embrapa.br/2010/doc/doc_292.pdf $>$. Acesso em: 09 jan. 2018

6 "O cenário vivenciado pela agricultura nos anos 80 que, de certa forma, se repetiu no início dos anos 90 , foi de crescimento da produtividade, com área relativamente constante, não obstante a escassez de crédito e a conjuntura de preços quase sempre desfavoráveis.". GONZALEZ. Bernardo Celso R. MARQUES. Pedro Valentim. A cédula de produto rural - CPR e seus ambientes contratual e operacional. Est. Econ. São Paulo. V. 29. N.1. Janeiro-Março 1999. p.65-94

7 BURANELO. Renato Macedo. Securitização do Crédito como Tecnologia para o Desenvolvimento do Agronegócio: Proteção Jurídica do Investimento Privado. Tese (Doutorado em Direito) - Faculdade de Direito - Pontifícia Universidade Católica de São Paulo. São Paulo: 2015. p. 82. Disponível em: $<$ http://www.sapientia.pucsp.br/tde_busca/arquivo.php?codArquivo=18689>. Acesso em 07 out. 2015.
} 
Ao acompanhar o sucesso da CPR, financiadores e os próprios integrantes do setor enxergaram suas vantagens e a necessidade de modernizar o aparato jurídico/financeiro existente a seu favor. Passaram, então, a pensar em novas soluções e títulos de crédito específicos para as relações jurídicas surgidas nos últimos anos, que pudessem servir melhor ao dia-a-dia do agronegócio do que os antigos e estanques títulos de crédito rural criados em meados do século passado, tais como as Duplicatas Rurais, as Cédulas Rurais Pignoratícias, as Cédulas Rurais Hipotecárias, as Notas de Crédito Rurais, etc.

O fruto dessa nova consciência foi a promulgação da Lei $\mathrm{n}^{0} 11.076 / 04$, conforme alterada, por meio da qual foram inseridos em nosso sistema jurídico novos títulos de crédito com foco em outras atividades típicas do setor, cada qual destinado a servir um determinado elo da cadeia do agroindustrial, a saber: (i) o CDCA; (ii) a LCA; e (iii) o CRA.

$\mathrm{Na}$ mesma oportunidade, foram criados o CDA e o WA para instituir um regime específico de títulos representativos de produtos depositados em armazéns agropecuários.

As novidades introduzidas pela Lei $\mathrm{n}^{\circ} 11.076 / 04$ permitiram que os participantes da cadeia agroindustrial pudessem se valer desses títulos para acessar a poupança popular no âmbito do mercado de capitais. Nesse cenário destacaram-se e vem ganhando cada vez mais espaço as operações de securitização de créditos do agronegócio, cuja prática popularizouse, entre outros e conforme veremos ao longo desta dissertação, por permitir maior segregação de risco entre as instituições participantes das operações financeiras ${ }^{8}$, proporcionando um aumento substancial na disponibilidade de capital para os que atuam no setor.

Nesse sentido, a criação dos títulos do agronegócio, bem como seu indispensável papel para o desenvolvimento do agronegócio brasileiro, ratificou a ideia de dinamicidade do direito comercial diante da constante evolução dos mercados $^{9}$, possibilitando a captação de investimentos de grandes dimensões para o desenvolvimento de um setor de suma

\footnotetext{
8 “(...) Por sua vez, sob a ótica jurídica, a securitização pode ser definida como a estrutura composta de um conjunto de negócios jurídicos - ou um negócio jurídico indireto - que envolve a cessão e segregação de ativos em uma sociedade ou um fundo de investimento emissor de títulos garantidos pelos ativos segregados. (...)”. Ibidem. p.167.

${ }^{9}$ A criação dos títulos de crédito do agronegócio demonstra a evolução do Direito Empresarial diante das necessidades que surgem no mercado. No que se refere ao contexto dinâmico em que se inserem as empresas na fase atual do Direito Empresarial, Rachel Sztajn explica: “(...) percebe-se que a fase atual do Direito Empresarial tem por foco, não mais, apenas, a figura da empresa, mas sim o binômio atividades empresáriasmercado. É neste prisma que se passa a cogitar da chamada ordem jurídica do mercado, já que, a partir de então, estuda-se a empresa em um contexto dinâmico, considerando-se o mercado, colocando-o como foco central desta disciplina jurídica. (...)” SZTAJN, Rachel. Teoria Jurídica da Empresa: Atividades Empresárias e Mercados. São Paulo: Atlas, 2004. p. 10.
} 
importância para a economia nacional. Com isso, afasta-se cada vez mais a dicotomia entre pequeno e grande produtor rural, bem como a separação estanque entre os setores de produção e agroindústria, dos mercados financeiro e de capitais, em direção a uma análise integrada e sistêmica de atividades agrícolas e financeiras.

Trazendo para o cenário presente, embora a economia brasileira tenha passado por dificuldades nos últimos anos, o agronegócio ostenta projeções de crescimento. O MAPA expediu o relatório de "Projeções do Agronegócio - Brasil 2015/2016 a 2025/2026"10, estimando que a produção de grãos deverá passar dos atuais 196 milhões de toneladas para 255 milhões de toneladas na safra projetada para 2025/2026. No mesmo sentido, a produção de carnes (bovina, suína e aves) deverá aumentar em 7,9 milhões de toneladas até 2025/2026.

Ainda que o setor permaneça atuando positivamente e se valendo dos mecanismos de financiamento privado desenvolvidos nas últimas quase duas décadas, vivemos novamente um momento de natural restrição de crédito e de políticas públicas de financiamento dos setores da economia em razão da instabilidade econômica, como a que o país tem atravessado, dificultando a captação de recursos para o desenvolvimento dos integrantes da cadeia agroindustrial. Nesse cenário, e graças aos instrumentos de financiamento privado trazidos pela Lei $n^{\circ} 8.929 / 94$ e Lei $n^{\circ} 11.076 / 04$, surgiram janelas de oportunidade para que os integrantes do setor captem recursos diretamente junto a poupança popular, valendo-se do mercado de capitais.

A entrada dos participantes do setor agroindustrial no mercado de capitais brasileiro, fortalecida nos últimos anos, especialmente por meio de operações de securitização (dentre as quais destacam-se aquelas envolvendo os CRA), viabilizou necessária queda dos juros na captação de recursos para financiamento do agronegócio, frente aos valores disponíveis para captação diretamente entre instituições financeiras e integrantes da cadeia no âmbito do mercado financeiro ${ }^{11}$.

\footnotetext{
${ }^{10}$ BRASIL. Ministério da Agricultura, Pecuária e Abastecimento. Projeções do agronegócio - Brasil 2015/16 a 2025/26 - http://www.agricultura.gov.br/assuntos/politica-agricola/todas-publicacoes-de-politicaagricola/projecoes-do-agronegocio/proj_agronegocio2016.pdf/@@download/file/Proj_Agronegocio2016.pdf >. Acesso em: 4. nov. 2017.

${ }^{11}$ Nesse sentido a Comissão de Valores Mobiliários demonstra a importância do bom funcionamento de ambos os mercados para a economia: "O mercado de crédito é fundamental para o bom funcionamento da economia, na medida em que as instituições financeiras assumem dois papéis decisivos. De um lado, atuam como centralizadoras de riscos, reduzindo a exposição dos aplicadores a perdas e otimizando as análises de crédito. De outro, elas funcionam como um elo entre milhões de agentes com expectativas muito distintas em relação a prazos e volumes de recursos. Quando o sistema inexiste ou existe de forma ineficiente, muitas das necessidades de aplicações e empréstimos de recursos ficariam represadas, ou seja, não circulariam no mercado, o que inevitavelmente causaria uma freada brusca na economia" (In. Comissão de Valores Mobiliários. O Mercado de Valores Mobiliários Brasileiro. 3. ed. Rio de Janeiro: Comissão de Valores Mobiliários, 2014. p. 32 e 33).
} 
Gráfico 1 - Volume de CRA Depositado/Registrado na B3 - Brasil, Bolsa, Balcão Segmento CETIP UTVM (RS milhões)

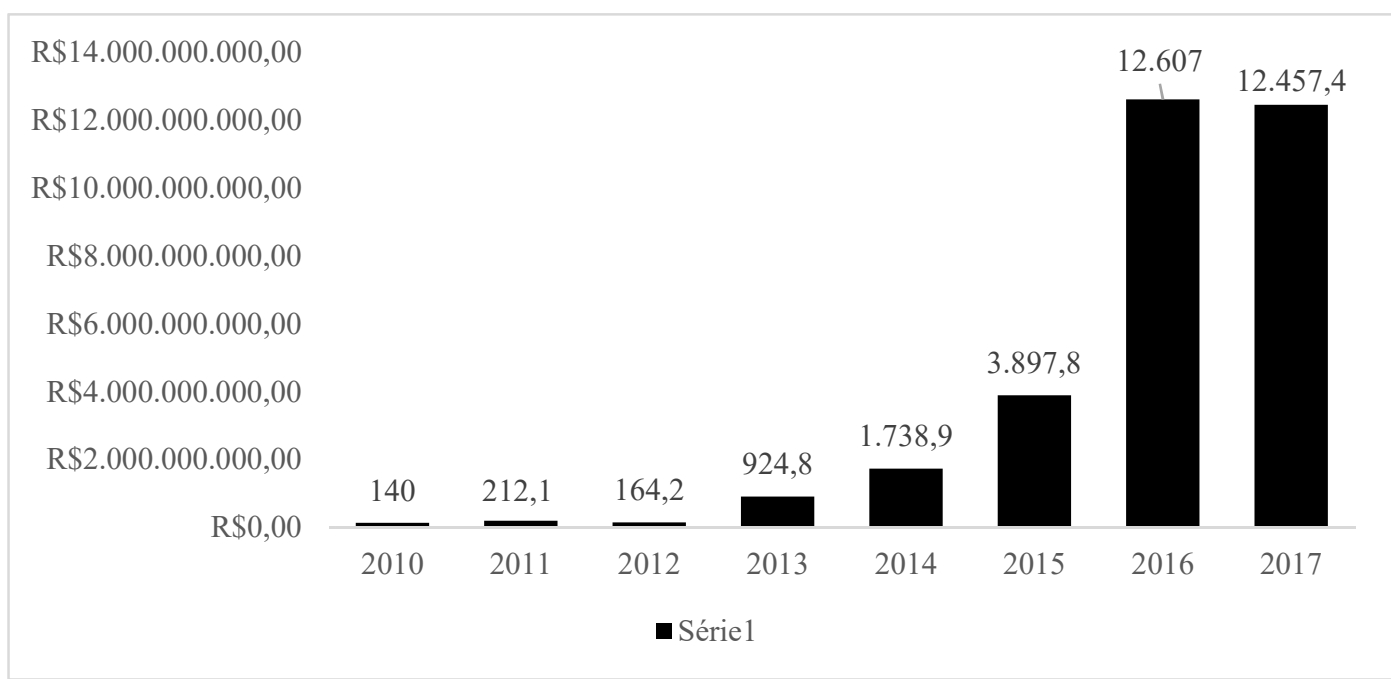

*Dados trabalhados pelo autor.

Consequentemente, a crescente demanda no agronegócio, bem como sua constante busca por novas fontes de captação de recursos, somada à multiplicidade de operações da cadeia agroindustrial que permitem originar direitos creditórios passíveis de vinculação às operações de securitização, depara-se com questões cada vez mais sofisticadas e carentes de discussão acadêmica.

Pelo acima exposto, esta dissertação objetiva aprofundar o estudo e as diversas discussões jurídicas que envolvem a securitização de direitos creditórios do agronegócio no Brasil, bem como sua contribuição para o financiamento de um dos principais setores da economia nacional.

No que se refere ao mercado de capitais, serão analisados conceitos como (i) poupança, investimento e intermediação financeira; (ii) estrutura do sistema financeiro nacional; (iii) histórico do mercado de capitais brasileiro e (iv) mobilização da poupança popular por meio do mercado de capitais.

Uma vez delineado o panorama geral acima descrito, serão expostos aspectos específicos do setor agroindustrial, de modo que, ao tratar da evolução da política de crédito agrícola no Brasil e a escassez de recursos provenientes de políticas públicas no financiamento do agronegócio, seja possível demonstrar a importância do surgimento de alternativas para o financiamento privado do setor agroindustrial. 
Após a fase expositiva acima, serão analisadas as características específicas de cada um dos títulos do agronegócio introduzidos pelas Leis $\mathrm{n}^{\mathrm{o}}$ 8.929/94 e 11.076/04, respectivamente, traçando um paralelo com os segmentos da cadeia agroindustrial aos quais visam beneficiar, bem como suas vantagens e desvantagens perante outras formas de financiamento.

Após explanados os títulos do agronegócio, será iniciada a fase de aprofundamento na securitização de créditos do agronegócio, iniciando pelos conceitos de valor mobiliário e Securitização. Nesse capítulo serão analisados aspectos jurídicos específicos sobre os CRA e os FIDC com lastro em direitos creditórios do agronegócio, trazendo discussões jurídicas atuais do dia-a-dia das operações mais complexas.

Dentre os principais temas trazidos nesse capítulo destacam-se a (i) ausência de previsão normativa para a circulação e cobrança de títulos de crédito escriturais; (ii) ausência de regulamentação específica para os CRA na CVM; (iii) o benefício fiscal aplicável aos titulares dos CRA; (iv) a polêmica definição do que seria "Cadeia Agroindustrial"; (v) a abertura de informações dos cedentes dos direitos creditórios do agronegócio; (vi) a remuneração dos CRA com base na variação cambial; (vii) direitos creditórios padronizados e não-padronizados; (viii) a liquidação pela entrega física de produto e (ix) "revolvência" do lastro no âmbito das ofertas de CRA e de cotas de FIDC.

Encerrada a análise, o estudo caminhará para sua conclusão, sintetizando os temas abordados ao longo da dissertação e buscando demonstrar a importância do estudo e da evolução da securitização de direitos creditórios do agronegócio para o desenvolvimento do setor agroindustrial. 


\section{CONCLUSÃO}

A securitização de créditos continua sendo uma das estruturas mais atrativas para tomadores de recursos junto aos mercados financeiro e de capitais. Apesar de custosa, do ponto de vista financeiro e de transação, a possibilidade de adiantar capital, tornar líquidos ativos financeiros que em geral não teriam destinação no curto prazo e tirá-los de seu balanço patrimonial têm contribuído para sua popularização. Isso sem contar os benefícios físcais aplicáveis a determinados títulos ou valores mobiliários incentivados, como é o caso dos Certificados de Recebíveis do Agronegócio - CRA, que isentam do imposto sobre a renda seus titulares, investidores pessoas físicas residentes no país ${ }^{124}$.

No início deste trabalho, verificamos a importância deste setor para a economia brasileira e os esforços legislativos realizados ao longo dos anos para que não faltassem recursos para a produção rural. Desde a criação do SNCR, foram diversas normas, programas e entidades criadas com o único intuito de permitir um ambiente estável e com recursos a sua disposição para o seu desenvolvimento.

Cumpre destacar o enfoque dado neste trabalho à diminuição da dependência única a exclusiva de recursos públicos e repasses para o desenvolvimento da agricultura e da pecuária como ocorria no passado, especialmente em razão da escassez de crédito em períodos turbulentos da economia brasileira, em especial ao final da década de 1980 e início dos anos 1990.

Nesse contexto, restou clara a impossibilidade de se depender de recursos públicos ou subsidiados para que os produtores rurais e demais integrantes do setor buscassem se financiar e então passaram a ser desenhadas iniciativas legislativas criando instrumentos financeiros modernos e adaptados às peculiaridades do agronegócio para permitir sua aproximação com financiamento privado.

Eis que surgem a CPR, por meio de Lei n 8.929, e os demais "novos" títulos do agronegócio em 2004, instituídos meio da Lei ${ }^{\circ}$ 11.076, que trouxeram não apenas novas

124 Para as pessoas físicas, desde $1^{\circ}$ de janeiro de 2005, os rendimentos gerados por aplicação em CRI estão isentos de imposto de renda (na fonte e na declaração de ajuste anual), por força do artigo $3^{\circ}$, inciso II, da Lei n. ${ }^{\circ} 11.033 / 04$. De acordo com a posição da Receita Federal, expressa no artigo 55, parágrafo único, da Instrução Normativa da Receita Federal do Brasil n 1.585, de 31 de agosto de 2015, tal isenção abrange, ainda, o ganho de capital auferido na alienação ou cessão dos CRI. 
modalidades de financiamento, mas ratificaram a ideia em construção de um setor amplo e interligado chamado de "agronegócio".

O agronegócio, complexo por natureza, constitui uma cadeia (ou rede) de negócios interdependentes, responsáveis por permitir que a produção ocorra, seja vendida, industrializada e atinja seus consumidores finais. Em razão de seus diversos participantes, o agronegócio é uma fonte quase inesgotável de negócios jurídicos geradores de fluxo de recebíveis, chamados para os fins jurídicos e deste trabalho de direitos creditórios, vinculáveis, portanto, às operações de securitização de créditos.

Conforme explicado no início nesta dissertação, tais operações configuram uma técnica de financiamento por meio da utilização de ativos financeiros ou direitos de crédito homogêneos - que por si só teriam baixa ou nenhuma liquidez - os quais são “empacotados” (agrupados) e cedidos em caráter definitivo (true sale) a um determinado veículo (seja uma companhia securitizadora, um fundo de investimento específico etc.), que os vincula a uma emissão de títulos ou valores mobiliários que serão posteriormente vendidos ou distribuídos no mercado financeiro e de capitais, conforme o caso.

Por mais que haja um veículo responsável pela emissão de títulos ou valores mobiliários, as operações de securitização, em geral, sujeitam aqueles que a ela aderem ao risco do negócio jurídico subjacente do qual derivam os direitos creditórios que a ela são vinculados, sendo estes os responsáveis pelo pagamento dos valores devidos aos investidores, e é nesse momento que surge a preocupação de se caracterizar perfeitamente do ponto de vista legal qual seria esse risco.

No início, as operações de securitização de créditos derivados de negócios realizados na cadeia do agronegócio eram quase que exclusivamente realizadas por meio de FIDC, os quais por uma questão regulatória apenas observam o requisito de serem créditos os ativos vinculados a eles vinculados. Com a entrada em vigor da Lei $\mathrm{n}^{\circ} 11.076$, outras figuras de securitização surgiram, mas no que se refere ao mercado de capitais brasileiro, ganhou destaque o CRA.

Diferentemente dos FIDC, e como vimos ao longo deste trabalho, os CRA demandam características próprias para que um direito creditório possa ser considerado como "do agronegócio" nos termos da lei, e portanto, vinculável a esses títulos, além de possuírem um tratamento tributário diferenciado, justamente para atrair o investimento privado - objeto de toda a reformulação jurídica que permeou a Lei n 11.076 .

Nesse diapasão surgiram diversas discussões jurídicas sobre os parâmetros da lei em comento para enquadramento desses créditos, as quais foram enfrentadas pela CVM, em 
conjunto com os participantes do mercado, proporcionando uma evolução positiva para o setor, as quais recentemente culminaram na Instrução CVM nº 600.

Entre as questões de maior destaque estão a (i) possibilidade de enquadramento como direitos creditórios do agronegócio os recebíveis derivados de dívidas daqueles que se relacionam com os produtores rurais ou suas cooperativas, desde que os recursos por eles captados sejam comprovadamente utilizados em favor do agronegócio no âmbito de relações jurídicas contratuais preexistentes com esses produtores ou cooperativas; e (ii) a possibilidade, para os CRA, de vinculação de recebíveis de prazos inferiores ao título ou valor mobiliário objeto da securitização, por meio de um mecanismo predeterminado de cessão de crédito e recompra programada como ocorre nos FIDC, permitindo que a dinâmica de recebíveis de curto prazo tão natural ao agronegócio possa também contar com essa alternativa de financiamento privado a longo prazo.

É claro que o instituto tem muito a ser desenvolvido em termos de eficiência e segurança jurídica. Uma discussão importante a se considerar é a que deriva da importância dada ao sujeito "produtor rural" no que se refere aos direitos creditórios do agronegócio para as operações de securitização envolvendo os CRA. Embora hoje haja um entendimento mais amplo do que poderia ser enquadrado no escopo do agronegócio, muitos negócios celebrados entre os chamados "terceiros" para fins da $\S 1^{\circ}$ do artigo 23 da Lei $n^{\circ} 11.076$ são inerentes à essa cadeia e não trariam a princípio uma fragilidade ou possível deturpação dos instrumentos criados para o financiamento do setor.

Um exemplo prático importante e discutido ao longo desse trabalho, foi a possibilidade de se considerar direitos creditórios do agronegócio os negócios realizados entre produtoras de insumos agrícolas e seus distribuidores ou revendas. Sem entrar em detalhes de uma discussão específica, é importante destacar que em alguns momentos, e pelo bem da evolução do instituto, deverá haver um "desapego" a separação estanque entre produtores rurais e terceiros, e nos atermos ao espírito da inovação legislativa trazida em 2004, que se voltou ao financiamento do agronegócio como um todo.

Logo, embora não haja necessariamente um produtor rural na relação primária de onde é derivado o fluxo de crédito a ser vinculado às operações de securitização envolvendo os CRA, a atividade geradora desses recebíveis não tem função outra que não abastecer ou promover o desenvolvimento do setor. Sendo assim, o que se propõe e parece importante concluir também nesta dissertação, é que deixemos de olhar o micro (sujeito) e passemos a olhar o macro (atividade) sob a ótica dos elos interdependentes do agronegócio, para que não sejam afastados de um meio de financiamento privado aqueles que o legislador 
claramente gostaria que se valessem das operações de securitização para promover o seu desenvolvimento.

A ideia é que ao longo do tempo se desonere as linhas de crédito subsidiadas ou os fundos públicos de grandes companhias agroindustriais que conseguem captar recursos mais baratos junto ao mercado de capitais dada a confiança que inspiram no público investidor, tornando seus papeis mais atrativos, de modo que tais linhas possam focar seus esforços nos pequenos e médios produtores rurais que tanto colaboram para o desenvolvimento do setor. Esse equilíbrio entre o financiamento público e privado é fundamental para que não haja escassez de recursos e uma interrupção evolutiva por consequência, e é na busca por esse balanço que o direito e a economia caminharam juntos para criar um novo e moderno arcabouço regulatório para o agronegócio.

Outro ponto bastante relevante é a necessidade de se reduzir os custos de transação inerentes aos processos de securitização de créditos, que hoje os tornam quase inacessíveis para tomadores de menor porte ${ }^{125}$. Com o tempo e a educação do mercado, o direito deve acompanhar as melhores práticas e enquadra-las dentro de uma moldura legal que permita sua evolução saudável, e um excelente exemplo nesse sentido foi a Instrução CVM n 600, que pacificou diversos procedimentos e conceitos em torno dos CRA, ou das constantes evoluções da Instrução CVM 356 no que se refere aos FIDC (algumas que o tornaram mais custoso, e outras buscando torna-lo novamente mais acessível).

De qualquer forma, é de se admirar a evolução do instituto ao longo dos últimos anos e sua relevância para o desenvolvimento do mercado de capitais nacional. A visão de que o agronegócio é composto apenas pelos pequenos produtores do campo já não reflete a realidade há anos, e um setor tão recheado de tecnologia e inteligência para enfrentar suas adversidades não poderia ficar fora da inovação financeira e jurídica da securitização de créditos. Espera-se poder ver mais discussões acadêmicas a esse respeito, para que cada vez mais integrantes dessa rede de negócios possam ter acesso a esse mecanismo de financiamento e não dependam de uma outra fonte para desempenharem suas atividades, afinal, o agronegócio está em todo lugar, e seremos todos beneficiados.

\footnotetext{
125 Basta pontuar poucos pontos para se avaliar o custo do processo como (i) prestadores de serviço (agência de classificação de risco, custódia dos ativos, escritórios de advocacia, auditores independentes etc.; (ii) comissões de estruturação financeira e distribuição; (iii) registros em cartório, registro junto à CVM e mercados onde os valores mobiliários forem distribuídos/negociados, quando for o caso; (iv) taxa mensal de custódia do lastro e dos títulos/valores, administração do patrimônio separado etc.
} 


\section{REFERÊNCIAS}

ABRÃO, Nelson. Direito Bancário. 14. ed. rev. atual. e ampliada pelo Desembargador Carlos Henrique Abrão. São Paulo: Saraiva, 2011

ALMEIDA, Luciana Florencio de. Ambiente institucional e contratos de crédito agrícola: três estudos críticos. Tese (Doutorado) - Faculdade de Economia, Administração e Contabilidade, Universidade de São Paulo, 2008.

ASCARELLI, Tullio. Teoria Geral dos Títulos de Crédito. Campinas, SP- Servanda Editora. 2009

ASSOCIAÇÃO NACONAL DAS INSTITUIÇÕES DO MEERCADO FINANCEIRO ANDIMA, CÂMARA DE CUSTÓDIA E LIQUIDAÇÃO CETIP. Estudos Especiais: Produto de Captação: FIDC: Fundo de Investimentos em Direitos Creditórios. Rio de Janeiro, 2006.

Estudos especiais: produtos de captação: CPR Cédula de Produto Rural. Rio de Janeiro. 2008.

. Estudos especiais: produtos de captação: títulos do agronegócio: CDA e WA: Certificado de Depósito Agropecuário e Warrant Agropecuário. Rio de Janeiro. 2008.

BARROS. José Eduardo Guimarães. FILHO. Celso Luiz Rocha Serra. $M E M O / N^{\circ}$ 286/2013/GJU-2/PFE-CVM/PGF/AGU, de 8 de novembro de 2013.

BANCO DO BRASIL., Diretoria de Agronegócios. Evolução histórica do crédito rural. In. Revista da Política Agrícola. Brasilia, out., nov, e dez. 2004.

BELIK. W. Paulillo, L.F. Mudanças no Financiamento da Produção Agrícola Brasileira. Disponível em: $<$ http://www.fao.org/tempref/GI/Reserved/FTP_FaoRlc/old/prior/desrural/brasil/Belik.PD F>. Acesso em: 09 jan. 2018 
BORGES, Luiz Ferreira Xavier. Securitização como parte da segregação do risco empresarial. Revista de Direito Bancário, do Mercado de Capitais e da Arbitragem n. 10, out./dez. 2000.

BRASIL. Ministério da Agricultura, Pecuária e Abastecimento. Projeções do agronegócio Brasil 2015/16 a 2025/26 - http://www.agricultura.gov.br/assuntos/politica-agricola/todaspublicacoes-de-politica-agricola/projecoes-doagronegocio/proj_agronegocio2016.pdf/@@download/file/Proj_Agronegocio2016.pdf >. Acesso em: 4. nov. 2017.

BULGARELLI. Waldirio. Títulos de crédito. 18. ed. São Paulo. Atlas. 2001

BURANELLO, Renato M. Sistema privado de financiamento do agronegócio - Regime Jurídico. São Paulo. Quartier Latin. 2011.

- Instrumentos para investimentos e o certificado de recebiveis do agronegócio/CRA. In. Revista de Direito Mercantil, vol. 148. 2009.

- Securitização do Crédito como Tecnologia para o Desenvolvimento do Agronegócio: Proteção Jurídica do Investimento Privado. Tese (Doutorado em Direito) Faculdade de Direito - Pontifícia Universidade Católica de São Paulo. São Paulo: 2015. Disponível em: $<$ http://www.sapientia.pucsp.br/tde_busca/arquivo.php?codArquivo=18689>. Acesso em 07 out. 2015.

. Manual do direito do agronegócio. São Paulo. Saraiva, 2013.

BURANELLO, Renato M. Instrumentos para Investimentos e o Certificado de Recebiveis do Agronegócio / CRA. Artigo publicado na Revista de Direito Mercantil, Industrial, Econômico e Financeiro n ${ }^{\circ}$ 148, outubro-dezembro de 2007.

CAMINHA, Uinie. Securitização. 2. ed. rev. e atual. São Paulo: Saraiva, 2007. 
. $1^{\mathrm{a}}$ ed. São Paulo: Saraiva, 2005.

CAMPOS, Diogo Leite e PINTO, Cláudia Saavedra. Créditos Futuros, Titularização e Regime Fiscal. Almedina, Coimbra 2007.

CANÇADO, Thais Romano; GARCIA, Fábio Gallo. Securitização no Brasil. São Paulo: Atlas, 2007.

CARSON, John. Self-regulation in securities markets. World Bank Policy Research Working Paper $5542 . \quad$ Disponível em: https://openknowledge.worldbank.org/bitstream/handle/10986/3313/WPS5542. pdf? sequence $=1$.

CARVALHO DE MENDONÇA, J.X. Tratado de Direito Comercial Brasileiro, 7 ed. Vol. V, Livro III,

CARVALHO, Maria Auxiliadora de, SILVA, César Roberto Leite da. Preços Mínimos e Estabilização de Preços Agrícolas. Revista de Política Econômica. Volume 13, no 1(49). Janeiro-Março de 1993.

CASTRO, Rodrigo. R. Monteiro, ARAGÃO, Leandro Santos de (Coords.). Direito societário e a nova lei de falências e recuperação de empresas. São Paulo: Quartier Latin, 2006.

CHALHUB, Melhim Namem. Negócio fiduciário. 4. ed. rev. e atual. Ed. Renovar. Rio de Janeiro, 2009.

. Trust. Rio de Janeiro. Renovar, 2001.

CNA - Confederação da Agricultura e Pecuária do Brasil. Agro mais maduro e moderno. Disponível em: http://www.cnabrasil.org.br/artigos/agro-maduro-e-moderno. Acesso em 17 maio. 2017 
COMISSÃO DE VALORES MOBILIÁRIOS. O Mercado de Valores Mobiliários Brasileiro. 3. ed. Rio de Janeiro: Comissão de Valores Mobiliários, 2014.

COVAS. Silvânio. O Título de Crédito Eletrônico e a Cédula de Crédito Bancário. In FONTES. Marcos Roli Fernandes \& WAISBERG. Ivo (coord.) - Contratos Bancários. São Paulo. Quartier Latin, 2006.

COX, James D.; HILLMAN, Robert W.; LANGEVOORT, Donald C. Securities regulation: cases and materials. New York: Aspen Publishers, 2009.

CHAVES, Natália Cristina. Direito Empresarial: securitização de crédito. Belo Horizonte: Del Rey, 2006.

DA SILVA. Ricardo Maia. DE OLIVEIRA. Reginaldo Pereira. Memorando $n^{\circ}$ 51/2015CVM/SRE/GER-1, de 25 de outubro de 2013. Disponível em: http://www.cvm.gov.br/export/sites/cvm/decisoes/anexos/0010/8782-2.pdf.

DA SILVA, João Calvão. Titularização de créditos - securitization: no coração da crise financeira global. Coimbra: Almedina, 2013.

DAVIDSON, Andrew et al. Securitization: structuring and investment analysis. New Jersey: John Wiley \& Sons, 2003.

DEACON, John. Global securitisation and CDO. John Wiley and Sons Ltd. West Sussex. 2004.

EIZIRIK, Nelson; GAAL, Ariádna B.; PARENTE, Flávia; HENRIQUES, Marcus de Freitas Henriques. Mercado de capitais - regime jurídico, Rio de Janeiro, Renovar, 2008. - Regulamentação e auto regulamentação do mercado de valores mobiliários. Revista de Direito Mercantil, Industrial, Econômico e Financeiro, São Paulo, São n. 48, 1982 . A Lei das S/A Comentada. V. I - Artigos $1^{\mathrm{a}}$ a 79. São Paulo. Quartier Latin, 2011. 
ESALQ/USP - Centro de Estudos Avançados em Economia Aplicada -. Índices de Exportação do Agronegócio $2017 . \quad$ Disponível em: $<$ https://www.cepea.esalq.usp.br/upload/kceditor/files/Cepea_ExportAgro_2017_(1).pdf $>$

FABOZZI, Frank J. Accessing capital markets through securitization. New Hope, Pennsylvania: Frank J. Fabozzi Associates, 1999.

FAGUNDES, João Paulo F. A. Os fundos de Investimento em direitos creditórios à luz das alterações introduzidas pela Instrução CVM 393. In Revista de Direito Mercantil, Industrial, Econômico e Financeiro. São Paulo: Malheiros. 2003.

FERREIRA, Waldemar. Tratado de Direito Comercial. v. 15. São Paulo. Saraiva, 1966.

FURLETTI. Mark. An overview of credit card asset-backed securities. Payment cards center discussion paper. Federal Reserve Bank of Philadelphia. Dezembro. 2002.

FRANCO, Vera H. de M.; SZTAJN. Rachel. Manual de direito comercial. Vols. 1 e 2. São Paulo: Editora dos Tribunais, 2005.

FRONTINI. Paulo Salvador. Títulos de Crédito Circulatórios: que futuro a informática lhes reserva? Revista dos Tribunais. São Paulo. 1996, agosto, v.85, nº 730.

GAGGINI, Fernando Schwarz. Securitização de Recebíveis. São Paulo. Ed. Universitária de Direito. 2003

GOETZMANN, William N. e ROUWEHHORST, Geert editores. The origins of value: the financial innovations that created modern capital markets. New York: Oxford University Press, 2005.

GOMES, Orlando. Obrigações. $16^{\mathrm{a}}$ ed. $3^{\mathrm{a}}$ tir. rev. atual. e aument., de acordo com o Código Civil, por Edvaldo Brito. Rio de Janeiro: Forense, 2004. 
GONÇALVES, José Siney. Agricultura sob a égide do capital financeiro: passo rumo ao aprofundamento do desenvolvimento dos agronegócios. In: Informações Econômicas, SP, abr. 2005.

GONZALEZ. Bernardo Celso R. MARQUES. Pedro Valentim. A cédula de produto rural CPR e seus ambientes contratual e operacional. Est. Econ. São Paulo. V. 29. N.1. JaneiroMarço 1999.

MAIA, Guilherme B.S. Sistemas Financeiros e Securitização: Implicações para a Política Monetária. Revista do BNDES, Rio de Janeiro, Vol. 15, n 30. in. AVELINO, Luiz Filipi de Cristófaro. Aspectos Jurídicos da Securitização no Brasil. Dissertação de Mestrado para obtenção de título na Faculdade de Direito da Universidade de São Paulo. 2014.

MICELI, Wilson Motta. CPR financeira: uma estratégia de hedge com opções de venda (artigo técnico). In: Resenha BM\&F n. 156 set. 2006.

MIRANDA, Pontes de. Tratado de direito privado. $3^{\text {a }}$ ed. Rio de Janeiro: RT, 1984, tomos I e V

HAZEN, Thomas Lee. The law of securities regulation. 6. ed. St. Paul: West, 2009.

HUDSON, Alastair. The Law of Finance. Londres: Sweet \& Maxwell, 2010.

KOTHARI, Vinod. Securitization: the financial instrument of the future. New Jersey: John Wiley \& Sons, 2006.

LAMY FILHO, Alfredo e PEDREIRA, José Luiz Bulhões (coord.). Direito das companhias. vol. I e II. Rio de Janeiro: Renovar, 1997.

LEÃES, Luiz Gastão Paes de Barros. O conceito de security no direito Norte Americano e o conceito análogo no direito Brasileiro. In: Revista de Direito Mercantil n.14

LE GOFF, Jacques. Marchands et banquiers du moyen âge. $9^{\mathrm{a}}$ ed. Paris: Press Universitaires de France, 2006. 
LOSS, Louis and SELIGMAN, Joel. Fundamentals of Securities Regulation, 5th ed., Library of Congress, Aspen Publishers : 2004.

LUCCA, Newton de; e SIMÃO FILHO, Adalberto. Direito e Internet Aspectos Jurídicos Relevantes. São Paulo. Edipro, 2000.

MASTROROCCO, Daniela. DE ANDRADE MELLO. Marcos Castro. Sistema de armazenagem de produtos agropecuários: emissão de certificado de depósito agropecuário (CDA) e warrant agropecuário (WA). In BURANELLO. Renato Macedo; SOUZA. André Ricardo Passos de; PERIN Junior. Ecio (Coord.) Direito do agronegócio: mercado, regulação, tributação e meio ambiente - São Paulo: Quartier Latin, 2011

MATTOS FILHO, Ary Oswaldo. O Conceito de Valor Mobiliário. Revista de Direito Mercantil, Industrial, Econômico e Financeiro, São Paulo- Revista dos Tribunais, n. 59. 1985.

MARTINS, Fran. Títulos de Crédito. Rio de Janeiro, RJ. Forense. 1999. $1^{\text {a }}$ Ed. Sob título "Letra de câmbio e nota promissória".

McINTYRE, Hal. How the U.S. securities industry works. 3. ed. Ottawa: The Summit Group Publishing, 2007.

MENDONÇA, José Xavier Carvalho de. Tratado de direito comercial brasileiro. Campinas: Bookseller, 2001.

MOSQUEIRA, Roberto Quiroga (Coord.). Aspectos atuais do Direito do Mercado Financeiro e de Capitais. São Paulo: Diatética, 1999.

PEDREIRA, José Luiz Bulhões. Finanças e demonstrações financeiras da companhia: conceitos e fundamentos. Rio de Janeiro: Forense, 1989.

PINHEIRO, Fernando Antonio Perrone. Securitização de recebíveis: uma análise dos riscos inerentes. 2008. 186 f. Dissertação (Mestrado). Universidade de São Paulo, São Paulo. 
PIRRONG. Craig. The economics of commodity trading firms. Trafigura. Houston. Março. 2014.

POSNER, Richard A. Economic Analysis of Law. Little, Brown and Company, Boston, 1992.

PROENÇA. José Marcelo Martins. Insider Trading. - Regime Jurídico do Uso de Informações Privilegiadas no Mercado de Capitais - São Paulo: Quartier Latin, 2005

RAMOS. Simone Yuri. Evolução da Política de Crédito Rural Brasileira/ Simone Yuri Ramos, Geraldo Buenoi Martha Júnior - Planaltina, DF: Embrapa Cerrados, 2010. Disponível em: <http://bbeletronica.cpac.embrapa.br/2010/doc/doc_292.pdf >. Acesso em: 09 jan. 2018

REQUIÃO, Rubens. Aspectos modernos de direito comercial: estudos e pareceres. São Paulo: Saraiva, 1977.

. Curso de direito comercial, vols. I e II. 10ª ed. São Paulo: Saraiva, 1981.

RIPERT, G. Aspectes Juridiques du Capitalism Moderne. Paris: LGDJ, 1977. .; ROBLOT, R. Traité Élémentaire de Droit Commercial. Paris: LGDJ, 2001.

ROCCA, Carlos Antonio (org.). Revolução no mercado de capitais brasileiro. Rio de Janeiro: Elsevier - IBMEC, 2008.

. Soluções do Mercado de Capitais para o Crescimento Sustentado. Rio de Janeiro: José Olympio, 2004 (Estudos IBMEC; 3)

RODRIGUES, Silvio. Direito Civil. $27^{\mathrm{a}}$ ed. ver. atual. São Paulo: Saraiva, 1999.

ROSSETI, J.P. Introdução à Economia. São Paulo: Atlas, 2003. 
SALOMÃO FILHO, Calixto. O novo direito societário. $3^{\text {a }}$ ed. rev. e ampl. São Paulo: Malheiros, 2006.

SAUNDERS, Anthony; WHITE, Lawrence J. Technology and the regulation of financial markets, securities, futures, and banking. Washington: Beardbooks, 2003.

SCRIBNER, Richard O. The technological revolution in securities trading: Can regulation keep up? In: Technology and the regulation of financial markets, securities, futures and banking. Washington: BeardBooks, 2003.

SICA. Ligia Paula Pires Pinto. GORGA. Erica. (coord.) Estudos avançados de direito empresarial: títulos de crédito. Rio de Janeiro. Elsevier, 2013.

SILVA, João Calvão da. Titularização de créditos - securitization: no coração da crise financeira global. 3. ed. rev. e aum. Coimbra: Almedina, 2013.

SOUZA, Adriano Boni de. Securitização de recebiveis da agroenergia: um estudo de caso baseado em títulos do agronegócio. Dissertação de Mestrado apresentada à Escola de Economia da Faculdade Getúlio Vargas, 2010. Disponível em: < https://bibliotecadigital.fgv.br/dspace/bitstream/handle/10438/7784/Adriano\%20Boni\%20d e\%20Souza.pdf?sequence=1\&isAllowed=y>. Acesso em 25 set. 2015.

SOUZA, André Ricardo Passos De. A tributação do certificado de depósito agropecuário e warrant agropecuário e a tributação. In BURANELLO. Renato Macedo; SOUZA. André Ricardo Passos de; PERIN Junior. Ecio (Coord.) Direito do agronegócio: mercado, regulação, tributação e meio ambiente - São Paulo: Quartier Latin, 2011.

STIGLITZ, Joseph E. (1996) Principles of microeconomics. W.W. Norton and Company, New York.

SZTAJN, Rachel. Teoria jurídica da empresa: atividade empresária e mercados. São Paulo: Atlas, 2004. 
VERÇOSA, Haroldo Malheiros Duclerc. Curso de direito comercial. v.1 a 5. São Paulo. RT, 2013.

. FRANCO. Nancy Gombossy de Melo Franco. Crédito e títulos de crédito na economia moderna: uma visão focada na cédula de produto rural - CPR", in Revista de Direito Mercantil, vol. 45, $\mathrm{n}^{\circ} 141$.

VIVANTE, Cesare. Instituições de direito comercial. Campinas: Editora Minelli, 2006.

Trattato di diritto commerciale. Milão, Casa Editrice Dott. Francesco Vallardi, vol.III,

WALD, Arnoldo. Comentários ao novo código civil. Do direito de empresa. Rio de Janeiro: Forense, 2005, v.19.

WEBER, Max. General economic history. translated by Frank H. Knight. New York: Dover Publications, Inc., 2003.

YAZBEK. Otavio. Regulação do mercado financeiro e de capitais. 2. ed. Rio de Janeiro, Elsevier : 2009.

O Risco de Crédito e os Novos Instrumentos Financeiros - uma análise funcional. In: WAISBERG, Rodrigo. FONTES, Marcos Rolim Fernandes (coord.). Contratos Bancários. São Paulo, Quartier Latin, 2006.

. Declaração de voto em 26 de novembro de 2013 no âmbito do Processo CVM . $^{\circ}$ RJ 2013/8860. (Reg. Col. n. ${ }^{o}$ 8782/2013). Disponível em: http://www.cvm.gov.br/export/sites/cvm/decisoes/anexos/0010/8782-1.pdf. Acesso em $1^{\text {o }}$ mai. 2018.

. BURANELLO. Renato. Parecer apresentado no âmbito do Processo CVM $n^{\circ} R J$ 19957.001669/2016-13, disponivel no Memorando no 61/2016-CVM-/SER/GER-1, de 29 de junho 2016.2 Disponível em: 
http://www.cvm.gov.br/export/sites/cvm/decisoes/anexos/2016/20160830/0291_SRE.pdf. Acesso em 12.05.2018

. O risco e crédito e os novos instrumentos financeiros - uma análise funcional. In: WAISBERG, Rodrigo. FONTES, Marcos Rolim Fernandes (coord.). Contratos Bancários. São Paulo, Quartier Latin, 2006.

ZYLBERSZTAJN, Decio; SZTAJN, Rachel. Direito e Economia. Rio de Janeiro: Elsevier, 2005 